\title{
Antiaging Property and Mechanism of Phase-Change Asphalt with PEG as an Additive
}

\author{
Huiru Wang, Yanmin Wang $(\mathbb{D}$, Xian Li, Min Chen, Yanling Wu, \\ Cuicui Sun, and Xiaoning Wang \\ School of Traffic and Civil Engineering, Shandong Jiaotong University, Jinan, Shandong Province 250300, China \\ Correspondence should be addressed to Yanmin Wang; ymwangsdu@139.com
}

Received 21 August 2020; Revised 18 October 2020; Accepted 6 November 2020; Published 23 November 2020

Academic Editor: Lingxue Kong

Copyright $\odot 2020$ Huiru Wang et al. This is an open access article distributed under the Creative Commons Attribution License, which permits unrestricted use, distribution, and reproduction in any medium, provided the original work is properly cited.

\begin{abstract}
In this study, phase-change asphalt was prepared with polyethylene glycol (PEG-1000) as a modifier. The short- and long-term antiaging performances were characterized by rolling-thin-film-oven (RTFOT) and pressure-aging vessel (PAV) tests, respectively. The functional groups and "bee structures" of PEG-modified asphalt and base asphalt were characterized by Fourier transform infrared absorption spectroscopy (FTIR) and atomic force microscopy (AFM). The research results indicate that the additive of PEG can improve the high-temperature, temperature sensitivity, and the antiaging properties of asphalt. The FTIR reveals that only physical blending and no chemical reaction occurs between PEG and asphalt. AFM topography indicates that smaller "bee structures" appear on the surface of PEG-modified asphalt and these structures do not change during aging.
\end{abstract}

\section{Introduction}

Asphaltic pavement has been widely applied as its excellent performance such as smooth surface, low vibration noise, comfortable driving, and low cost in highway construction [1]. However, as temperature sensitive material, the properties of asphalt and asphalt mixture are limited by temperature variation. Asphalt will be softened when the environmental temperatures are extremely high. Asphalt pavement belongs to the black road surface, which is easy to absorb solar radiation heat. In summer, series of hightemperature problems such as rutting, upheaval, aging, and fatigue can appear because of the sun's radiation or overheat. In addition, the urban road system is covered with the urban fabric, which impedes road radiation and heat diffusion known as "urban heat island effect" [2]. In order to relief this "heat-island effect," one of the effective measures is to lower the asphalt pavement temperature.

In order to take corresponding measures to deal with negative effects caused by extreme temperature changes of asphalt pavements [3], many methods such as application of various modified asphalt and antirutting agents, optimizing the aggregate grade, and the mix design have been proposed by researchers. Among them, the incorporation of additive in asphalt is an effective way to improve high-temperature performance of asphalt. Based on previous studies from home and abroad, the thermal effect caused by phase change is a vital component in the control of pavement temperature. The research results indicate that the effect of temperature on asphalt can be alleviated by adding phase change materials (PCMs) into asphalt [4].

In order to reduce the occurrence of freezing, Xavier et al. $[5,6]$ introduced n-tetradecane paraffin (the curing temperature was $2^{\circ} \mathrm{C}$ or $5^{\circ} \mathrm{C}$ ) into the surface course of road pavement. Zhu [7], Zhou et al. [8], Ye [9], and others mainly focus on improving the temperature stability and durability of asphalt mixture. Through comprehensive thermal analysis and infrared spectroscopy, Zhang et al. [10] selected phase change materials suitable for asphalt concrete pavement by analysing the high-temperature properties of various phase change materials.

Polyethylene glycol (PEG) can be used as an asphalt modifier due to its suitable phase change temperature and higher enthalpy of phase change. PEG [11], as an organic phase-change thermal storage material, has superior thermal resistance, a large heat-storage coefficient, and greater 
thermal inertia index. Its general phase change temperature is $30 \sim 60^{\circ} \mathrm{C}$, which depends on molecular weight. Therefore, the effective way, to improve the temperature stability of asphalt and asphalt mixture and reduce the rutting of asphalt pavement at high temperatures, is to add PEG into asphalt. The urban heat-island effect and specific road problems can be mitigated.

Therefore, in this work, we focus herein on research into the mechanism by which PEG modifies the performance of asphalt. To facilitate the latter promotion of applications, a commercially available PEG without any pretreatment was selected as a modifier, the commonly used asphalt A-70 was selected as base asphalt, and we prepared asphalt modified by various doses of PEG. Physical properties, antiaging characters, low-temperature performances, and thermal performance properties were studied. To investigate the modification mechanism, microscopic characterizations of AFM and Fourier transform infrared spectroscopy (FTIR) tests were used to detect the surface topography and the changes in functional groups of asphalt before and after the aging, respectively.

\section{Materials and Methods}

2.1. Preparation of PEG-Modified Asphalt. The asphalt A-70 was provided by Shandong Hi-Speed Construction Materials in Shandong Province, China. The polyethylene glycol (PEG1000, AR) with the heat conductivity $0.3 \sim 0.5 \mathrm{~W} /(\mathrm{m} \cdot \mathrm{K})$ and phase change temperature $30 \sim 60^{\circ} \mathrm{C}$, purchased from Shanghai Macklin Biochemical Co., Ltd., China, is about 1000 of molecular weight. The molecular formula of PEG is $\mathrm{HOCH}_{2}\left(\mathrm{CH}_{2} \mathrm{OCH}_{2}\right) \mathrm{nCH} \mathrm{CH}_{2} \mathrm{OH}$ with a linear molecular structure $[12,13]$. Table 1 lists the physicochemical parameters of PEG-1000.

A high-speed shear machine was used to prepare modified asphalt. The preparation of PEG-modified asphalt is as follows. First, the A-70 asphalt was heated to a flowing state $\left(\sim 125^{\circ} \mathrm{C}\right)$ in an iron chamber. Next, to ensure a uniform dispersion, the PEG was fed into the asphalt gradually. Once the PEG was fed into the asphalt, the mixture was sheared at $3000 \mathrm{rpm}$ at $145^{\circ} \mathrm{C} \sim 150^{\circ} \mathrm{C}$ for $30 \mathrm{~min}$ to produce the final modified asphalt. The modified asphalt with $5 \%, 10 \%$, and $15 \%$ PEG in weight was then prepared.

\subsection{Testing of Basic Properties of Asphalt. Based on "Standard} Test Methods of Bitumen and Bituminous Mixtures for Highway Engineering" (JTG E20, Chinese Industrial Standards of the People's Republic of China, 2011), the penetration, ductility, and softening point of the modified asphalt were tested. The temperatures of penetration experiments were set at $5^{\circ} \mathrm{C}, 15^{\circ} \mathrm{C}$, and $25^{\circ} \mathrm{C}$, respectively. The temperature of ductility experiments was set at $15^{\circ} \mathrm{C}$. The starting temperature of softening point experiment was $5^{\circ} \mathrm{C}$. The viscosity at $135^{\circ} \mathrm{C}$ was determined by Brookfield viscometer (Brookfield, RVDV-II + P, USA), and the short- and longterm aging tests were done by RTFOT and PAV, respectively.

2.3. BBR Testing. The bending beam rheometer (BBR) test (CANNON, TE-BBR-F, USA) was operated on the PAV- aged samples, which was used to investigate the low temperature performances.

The description of asphalt aging level was often evaluated by the measured creep stiffness ( $s$-value) and rate of relaxation ( $m$-value). Three low temperature grades (that is, $-6,-12$, and $-18^{\circ} \mathrm{C}$ ) were conducted on the asphalt binder. Two parallel tests were carried on each binder type when testing the deflection, stiffness, and $m$-value under the constant load and constant temperature.

2.4. Testing of Temperature Adjustment. According to the literature [4], the temperature adjustment property of the asphalt samples was investigated. The detailed testing procedure is as follows. The undertest asphalt with flowing state was put into the penetration test vessel. A digital thermometer (LGR-wd41, the accuracy is $\pm 0.1^{\circ} \mathrm{C}$ ) was bedded in the specimen. When the specimens were thoroughly cooled down to room temperature, they were transferred into thermostatic equipment with a constant temperature of $60^{\circ} \mathrm{C}$. The temperature variation of each specimen was recorded by the digital thermometer every five minutes.

2.5. FTIR and AFM Measurements. FTIR absorption spectroscopy (Bruker Tensor 27, Germany) from 400 to $4000 \mathrm{~cm}^{-1}$ with a resolution of $4 \mathrm{~cm}^{-1}$ was conducted on the base asphalt and the modified asphalt before and after aging to determine the functional groups $[14,15]$. Before acquiring FRIT spectra, all samples were ground with potassium bromide powder until the solvent evaporated completely.

An AFM (Bruker Nano (Santa Barbara, California) Multimode 8 with nanoscope software) was engaged in checking the morphology of the asphalt before and after aging. AFM samples were prepared by a hot-casting method which involved dipping a glass rod into melted asphalt and dropping the asphalt onto a glass slide $\left(10 \times 10 \times 1 \mathrm{~mm}^{3}\right)$. The glass slide with asphalt was then placed and tilted about $30^{\circ}$ above the horizontal in an oven at $150^{\circ} \mathrm{C}$ for 15 minutes so that the asphalt flowed and spread on the surface of the glass slide under the action of gravity. Finally, the asphalt films could be collected when they were in the ambient temperature.

\section{Results and Discussion}

3.1. Analysis of the Asphaltic Basic Properties. Table 2 shows the penetration, softening point, ductility, and viscosity of PEG-modified asphalt with different contents $(0 \%, 5 \%, 10 \%$, and $15 \%$ by weight of an asphalt binder) are shown in Table 2.

From Table 2, it can be seen that the admixture of PEG results in the decreasing ductility, increasing penetration, increasing viscosity, and enhancing the softening point slightly.

It is well known that one of the parameters to characterize the flexibility of asphalt at low temperature is the ductility. Ductility is proportional to the flexibility of asphalt. [16]. In addition, the saturated phenols and aromatic compounds exhibited an increasing trend with the 
TABLE 1: The physicochemical parameters of PEG-1000.

\begin{tabular}{lccccc}
\hline & Relative molecular weight & $T_{0 n}\left({ }^{\circ} \mathrm{C}\right)$ & $T_{p}\left({ }^{\circ} \mathrm{C}\right)$ & $T_{\text {end }}\left({ }^{\circ} \mathrm{C}\right)$ & $\Delta H_{m}(\mathrm{~J} / \mathrm{g})$ \\
\hline PEG (1000) & $950 \sim 1050$ & 29 & 45.6 & 76.7 & 78.6 \\
\hline
\end{tabular}

Note. $T_{0 n}$ : initial temperature of phase transition; $T_{p}$ : phase change temperature peak; $T_{\text {end: }}$ phase transition termination temperature; $\Delta H_{m}$ : enthalpy of phase change.

TABLe 2: Effects of different PEG on physical properties of asphalt.

\begin{tabular}{|c|c|c|c|c|c|}
\hline \multirow{2}{*}{ Index } & & \multicolumn{4}{|c|}{ PEG content $(\%)$} \\
\hline & & 0 & 5 & 10 & 15 \\
\hline \multirow{3}{*}{ Penetration $(100 \mathrm{~g}, 5 \mathrm{~s})(0.1 \mathrm{~mm})$} & $15^{\circ} \mathrm{C}$ & 25 & 27 & 33 & 40 \\
\hline & $25^{\circ} \mathrm{C}$ & 65 & 79 & 98 & 115 \\
\hline & $30^{\circ} \mathrm{C}$ & 108 & 110 & 128 & 134 \\
\hline Softening point $\left({ }^{\circ} \mathrm{C}\right)$ & & 53.0 & 48.5 & 49.0 & 53.0 \\
\hline Ductility $\left(5 \mathrm{~cm} / \mathrm{min}, 15^{\circ} \mathrm{C}\right)(\mathrm{cm})$ & & 150 & 135 & 119 & 107 \\
\hline Viscosity $\left(135^{\circ} \mathrm{C}, \mathrm{mPa} \cdot \mathrm{s}\right)$ & & 364 & 403 & 432 & 490 \\
\hline
\end{tabular}

increasing content of PEG, which leads to the cohesion between the asphalt molecules weakening. When the asphalt is stretched by external forces, it is easy to fracture. With the increasing PEG content, the volume fraction of the discontinuous dispersion system increases, and the plastic deformation capacity and ductility decrease. With PEG dispersing in the asphalt system, the consistency of asphalt reduces, and the molecular motion of asphalt has been promoted, which improves the penetration of PEG-modified asphalt. The softening point of asphalt is directly proportional to its high temperature stability. PEG, with the phase change temperature range of $30^{\circ} \mathrm{C}$ to $60^{\circ} \mathrm{C}$, includes the softening point of asphalt into the asphalt system. When PEG-modified asphalt underwent phase change and absorbed heat, the temperature remained basically unchanged for a period of time, which reduced the heat absorbed by asphalt and effectively slowed down the heating rate of asphalt. The time of the softening point of asphalt was delayed, and the softening point increased.

The penetration index (PI) of asphalt, which can evaluate the sensitivity of asphalt to temperature, is calculated based on the penetrations from different temperatures. The larger the PI is, the less sensitive of asphalt will be to temperature. The penetrations from different temperatures $\left(15^{\circ} \mathrm{C}, 25^{\circ} \mathrm{C}\right.$, and $30^{\circ} \mathrm{C}$ ) are tested and shown in Table 1 . The PI of asphalt was calculated by using formulas (1) and (2) [17]. The results are shown in Figure 1:

$$
\begin{aligned}
\operatorname{Lg} P & =K+\text { AlgPen } \times T, \\
\text { PI } & =\frac{(20-500 \text { AlgPen })}{(1+50 \text { AlgPen })},
\end{aligned}
$$

where $P$ is penetration at the corresponding test temperature $T(0.1 \mathrm{~mm}) ; K$ is the constant term of the regression equation; and AlgPen is the coefficient of linear regression equation.

As can be concluded from Figure 1, the admixture of PEG increases PI, which means that the larger the PI is, the smaller the temperature sensitivity of asphalt will be.

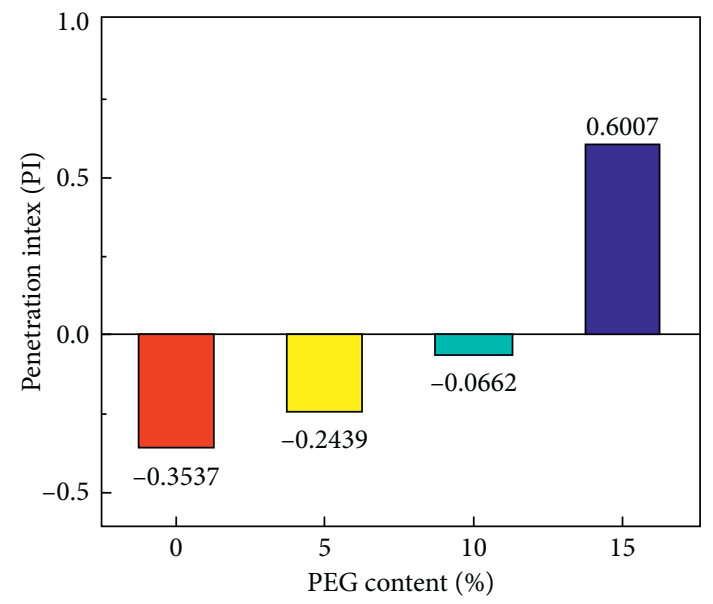

FIgURE 1: Effects of different PEG dosage on the penetration indexes (PIs).

The solid-liquid phase transformation would occur at the high temperature during the investigation of phase change modified asphalt, which makes the temperature stay basically the same for a while. Therefore, the phase change endothermic process can decrease the temperature sensitivity of asphalt.

3.2. Short-Term Aging Properties of PEG-Modified Asphalt. In current asphalt pavement construction specifications in China, the properties before and after through antiaging indexes can study the antiaging property of modified asphalt and the base asphalt [18]. Short-term aging was done in the RTFOT at $163^{\circ} \mathrm{C}$ for $85 \mathrm{~min}$, and the penetration $(P)$, viscosity $(V)$, ductility $(D)$, and softening point (SP) of the residues were measured. The antiaging properties were evaluated based on the penetration ratio $K_{P}$, ductility ratio $K_{D}$, viscosity ratio $K_{V}$, and SP increment $\Delta \mathrm{T}$, which were calculated by using formulas (3)-(6). The results are listed in Table 3 and Figure 2. In formulas (3)-(6), the subscripts 1 and 2 refer to before and after short-term aging, respectively:

$$
\begin{gathered}
K_{P}=\frac{P_{2}}{P_{1}} \times 100, \\
K_{D}=\frac{D_{2}}{D_{1}} \times 100, \\
K_{V}=\frac{V_{2}}{V_{1}} \times 100, \\
\Delta_{T}=T_{2}-T_{1} .
\end{gathered}
$$


TABle 3: Effects of different PEG dosage on antiaging properties of asphalt.

\begin{tabular}{|c|c|c|c|c|c|}
\hline & \multirow{2}{*}{ Index } & \multicolumn{4}{|c|}{ PEG content (\%) } \\
\hline & & 0 & 5 & 10 & 15 \\
\hline \multirow{8}{*}{ Aging states } & Penetration $\left(25^{\circ} \mathrm{C}, 100 \mathrm{~g}, 5 \mathrm{~s}\right)(0.1 \mathrm{~mm})$ & 65 & 79 & 98 & 115 \\
\hline & Softening point $\left({ }^{\circ} \mathrm{C}\right)$ & 53.0 & 48.5 & 49.0 & 53.0 \\
\hline & Ductility $\left(5 \mathrm{~cm} / \mathrm{min}, 15^{\circ} \mathrm{C}\right)(\mathrm{cm})$ & 150 & 135 & 119 & 107 \\
\hline & Viscosity $\left(135^{\circ} \mathrm{C}, \mathrm{mPa} \cdot \mathrm{s}\right)$ & 364 & 403 & 432 & 490 \\
\hline & Penetration $\left(25^{\circ} \mathrm{C}, 100 \mathrm{~g}, 5 \mathrm{~s}\right)(0.1 \mathrm{~mm})$ & 34 & 39 & 45 & 56 \\
\hline & Softening point $\left({ }^{\circ} \mathrm{C}\right)$ & 55.0 & 50.5 & 50 & 55.5 \\
\hline & Ductility $\left(5 \mathrm{~cm} / \mathrm{min}, 15^{\circ} \mathrm{C}\right)(\mathrm{cm})$ & 13.7 & 12.7 & 15.4 & 11.3 \\
\hline & Viscosity $\left(135^{\circ} \mathrm{C}, \mathrm{mPa} \cdot \mathrm{s}\right)$ & 635 & 725 & 821 & 833 \\
\hline \multicolumn{2}{|l|}{ Penetration ratio $\left(K_{p}\right)(\%)$} & 52.3 & 52.4 & 53.9 & 52.7 \\
\hline \multicolumn{2}{|l|}{ Ductility ratio $\left(K_{D}\right)(\%)$} & 9.1 & 9.4 & 12.9 & 10.6 \\
\hline \multicolumn{2}{|l|}{ Viscosity ratio $\left(K_{V}\right)(\%)$} & 1.7 & 1.8 & 1.9 & 1.7 \\
\hline \multicolumn{2}{|l|}{ SP increment $(\Delta \mathrm{T})\left({ }^{\circ} \mathrm{C}\right)$} & 2 & 2 & 1 & 2.5 \\
\hline
\end{tabular}
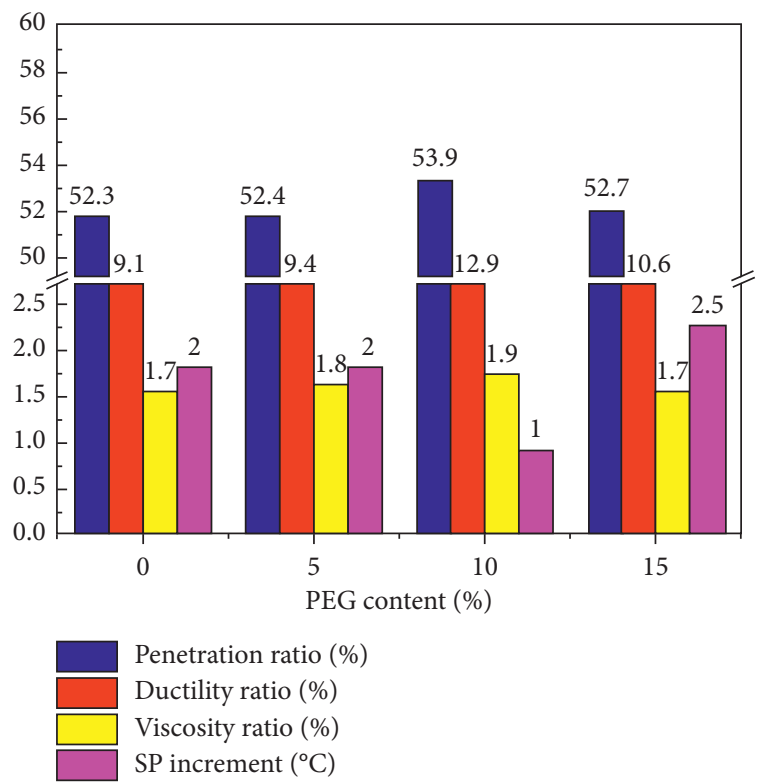

FIGURE 2: Effects of different PEG dosage on antiaging properties of asphalt.

The RTFOT aging test can stiffen the asphalt, which manifests an increase in viscosity and softening point, a decrease in ductility and penetration. Therefore, the antiaging performance can be evaluated from the side view by $K_{P}, K_{D}, K_{V}$, and the SP increment $\Delta \mathrm{T}$ of asphalt before and after aging. Larger values of $K_{P}, K_{D}$, and $K_{V}$ and a smaller $\Delta \mathrm{T}$ correspond to better antiaging performance. As can be seen from Table 3 and Figure $2, K_{P}, K_{D}$, and $K_{V}$ first rise and then fall, and are higher than the base asphalt. In conclusion, the addition of PEG improved the antiaging property of modified asphalt, and the best PEG dose is $10 \%$.

The light components in the asphalt will be volatiled during the process of asphalt aging. PEG is an organic phase change material with excellent thermal resistance and large heat storage coefficient. It can produce larger latent heat as the temperature rises. PEG has little or no change in temperature during phase transition, but it has the ability to store and release large amounts of heat, which makes the heat absorption by the asphalt reduce and retards the heating rate of asphalt interior effectively. Therefore, the thermoregulation performance of PEG-modified asphalt has been realized. Concretely speaking, the colloid structure of asphalt was changed because of the direct incorporation of PEG [19-21]. During the mixing process, due to the high temperature (above $130^{\circ} \mathrm{C}$ ), the solid PCM absorbs excess heat and becomes liquid. However, then, mostly they were easy to transfer, reducing the consistency and decreasing the saturated content of asphalt significantly when the content of PEG is more than $10 \%$. The trend of increasing the antiaging property of asphalt was not obvious, which increases the possibility of asphalt pavement deformation and changes its road performance.

3.3. BBR Analysis. Under low-temperature environment, asphalt pavement is prone to forming cracks. The lowtemperature crack resistance properties are often evaluated by BBR analysis. BBR tests at low temperature were conducted on PAV aged PEG-modified asphalt with different dosages and base asphalt according to the American Association of State Highway and Transportation Officials (AASHTO 2012) T313-12 [22, 23]. According to the requirements of the Strategic Highway Research Program (SHRP), the target value of $S$ and $m$ is $<300 \mathrm{Mpa}$ and $>0.3$, respectively. The BBR results are shown in Figure 3.

As shown in Figure 3, with the reduction of test temperature, the creep stiffness of PAV aged PEG-modified asphalt with different doses increased rapidly while the creep rate decreased. Figure 3 shows that the admixture of PEG does not change the creep stiffness obviously and enhances the creep rate at the same temperature, which indicates that the asphalt becomes harder with the decreasing temperature. If the temperature is lowered to $-18^{\circ} \mathrm{C}$, the values of creep stiffness $(S)$ and creep rate ( $m$-value) cannot meet the SHRP specification target values of $S<300 \mathrm{MPa}$ and $m>0.3$, which indicates that the temperature of $-18^{\circ} \mathrm{C}$ is the breaking temperature of PEG-modified asphalt. The creep rate of the BBR test is often used as the evaluation index of lowtemperature shrinkage crack. When the creep rate is greater, the stress relaxation and crack resistance abilities of asphalt 


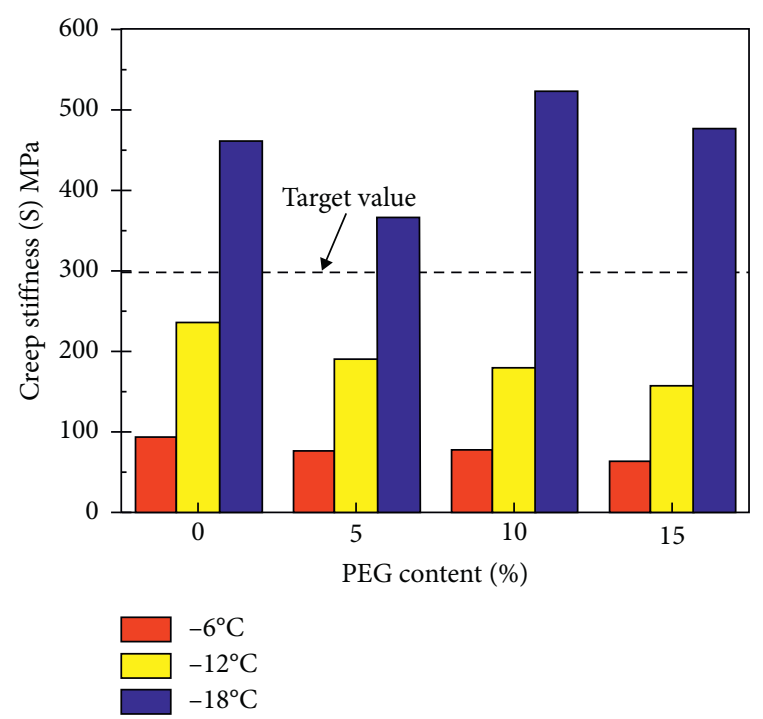

(a)

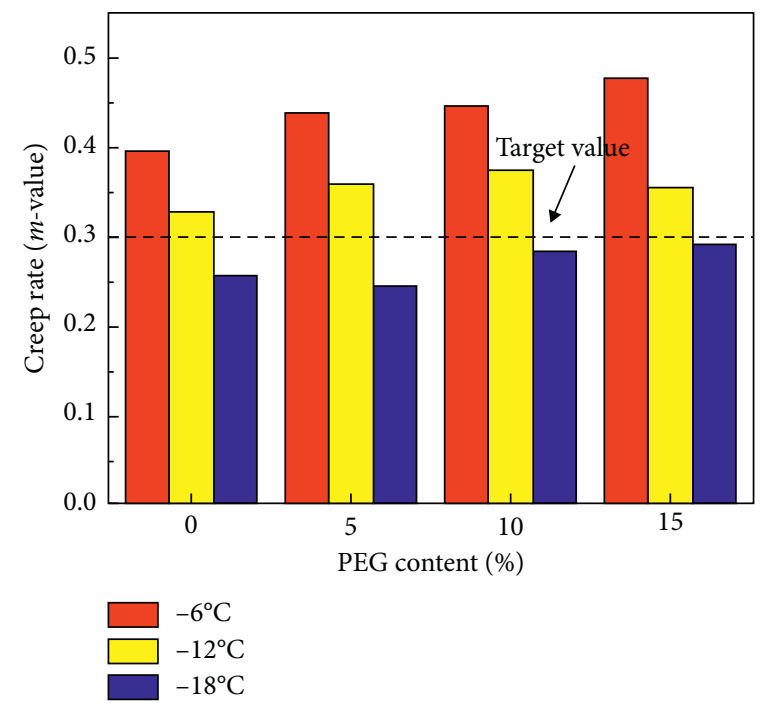

(b)

FIGURE 3: Effects of different PEG dosage on bending beam rheometer (BBR) tests of creep stiffness (a) and creep rate (b) of PAV aged PEGmodified asphalt.

will be better $[24,25]$. The low-temperature crack resistance of PAV aged PEG-modified asphalt does not decrease compared with that of PAV aged matrix asphalt.

3.4. Temperature Regulation of PEG-Modified Asphalt. The modification effect of PEG on base asphalt is mainly reflected in the aspect of heat absorption and temperature delay when the asphalt is in the high-temperature period [26]. To examine the thermal performance properties of asphalt modified by various dosages of PEG, the temperature regulation research methodology was used which was tested in water at $60^{\circ} \mathrm{C}$. Figure 4 shows the temperature variations of asphalt samples prepared with different contents of PEG $(0 \%, 5 \%, 10 \%$, and $15 \%)$ with temperature increasing in the lab.

Figure 4(a) shows that the temperature variation of asphalt with different dosages of PEG. The drop in temperature is the most obvious when the dosage of PEG is $10 \%$. The temperature difference between the asphalt with $10 \%$ PEG and the base asphalt is shown in Figure 4(b). The highest temperature difference is $13.5^{\circ} \mathrm{C}$.

The phase change heat storage process of PEG at a certain temperature, which leads to a phase change thermoregulation, made a phase change thermoregulation in the PEG-modified asphalt. When the heating temperature of asphalt increases and reaches the phase change temperature of PEG, PEG will absorb abundant heat and change the phase state, which impedes the heat absorption and the heating rate of asphalt. The temperature-regulating ability of PEG-modified asphalt is directly proportional to the mixing amount when PEG content is less than $15 \%$. The effect of temperature adjustment is restricted when the content of PEG is $5 \%$. However, the temperature-regulating ability was also restricted when the content of PEG was $15 \%$. It is chiefly because the high content of PEG made the viscosity increased significantly and the phase transition of PEG was limited. A large amount of PEG has limited the heat transfer effect of asphalt and destroyed the continuity of base asphalt when PEG-modified asphalt was in a thin viscous state.

\subsection{Anti-Ultraviolet Radiation Aging Mechanism Analysis}

3.5.1. FTIR Analysis. In order to deeply analyse and study the mechanisms of how the PEG admixture affects aging in microlevel, FTIR absorption spectroscopy was operated to investigate the functional groups. Figure 5 shows the FTIR spectra of the PEG, base asphalt, and modified asphalt, both before and after RTFOT and PAV aging [27-29].

Figures 5(a)-5(c) show the FTIR absorption spectrum of PEG, the A-70 base asphalt, and the unaged 10\% PEGmodified asphalt, respectively. In the spectrum of the A-70 base asphalt, as for the unaged A-70 base asphalt, absorption in the region of $2922-2855 \mathrm{~cm}^{-1}$ be ascribed to the stretching vibration of the $-\mathrm{CH}_{2}$ - group. Absorption between $1452 \mathrm{~cm}^{-1}$ and $700 \mathrm{~cm}^{-1}$ is due to the bending vibration of $\mathrm{C}-\mathrm{H}$, which can confirm the saturated hydrocarbon in the asphalt [30]. The peaks located at $842 \mathrm{~cm}^{-1}$ and $957 \mathrm{~cm}^{-1}$ are attributed to the bending vibration of $-\mathrm{CH}_{2} \mathrm{CH}_{2} \mathrm{O}-$ and $-\mathrm{C}$ $\mathrm{O}-\mathrm{C}$ - functional groups, respectively. The peaks located at $1112 \mathrm{~cm}^{-1}$ and $1147 \mathrm{~cm}^{-1}$ are because of the stretching vibration of $-\mathrm{C}-\mathrm{O}$. The peaks located at $1242 \mathrm{~cm}^{-1}$ and $1281 \mathrm{~cm}^{-1}$ are ascribed to the $-\mathrm{OH}$ stretching vibration. The bending vibration of $-\mathrm{CH}_{2}$ and $-\mathrm{CH}_{3}$ groups is indexed as the peaks located at the $1342 \mathrm{~cm}^{-1}$ and $1469 \mathrm{~cm}^{-1}$, respectively. The stretching vibration of $-\mathrm{CH}_{2}$ and $-\mathrm{OH}$ groups is located at $2896 \mathrm{~cm}^{-1}$ and $3436 \mathrm{~cm}^{-1}$, respectively [31]. Furthermore, no new absorption peak appears in the FTIR spectrum of PEG-modified asphalt (see Figure 5(c)); the only difference is the intensity of some peaks. From Figure 5(c), most of absorption peaks of the main functional groups of 


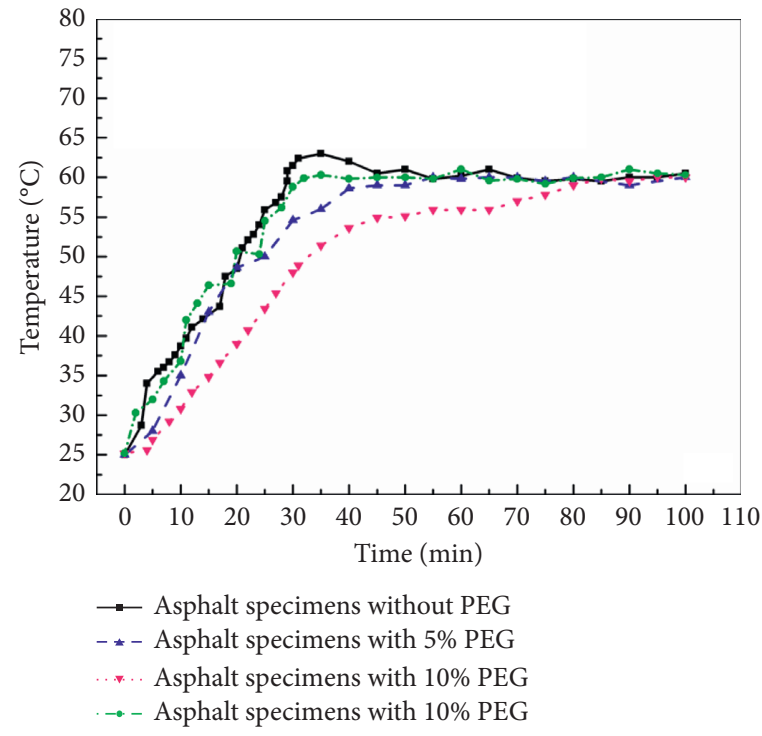

(a)

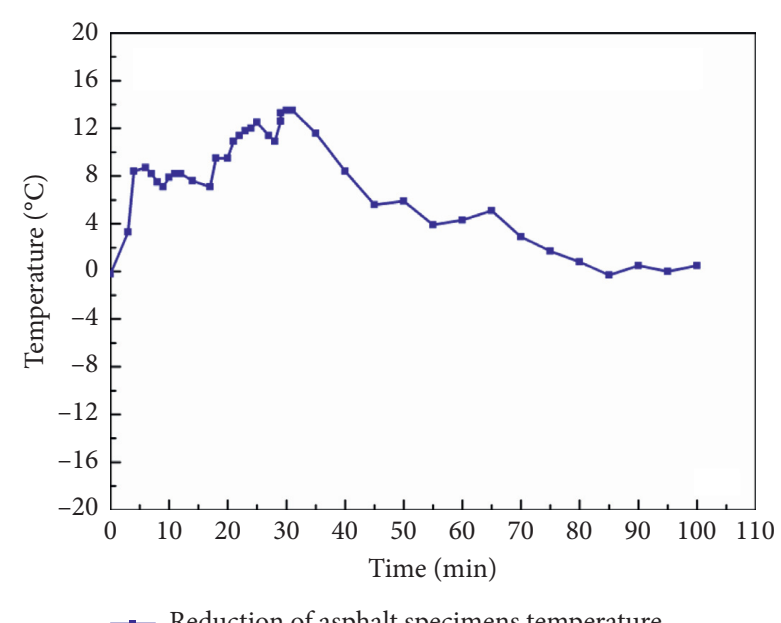

- Reduction of asphalt specimens temperature

(b)

FIgURE 4: The temperature collection. Temperature differences in the lab (a) and the reduction of the temperature in the lab (asphalt specimen without PEG vs PEG-modified asphalt with 10\%) (b).

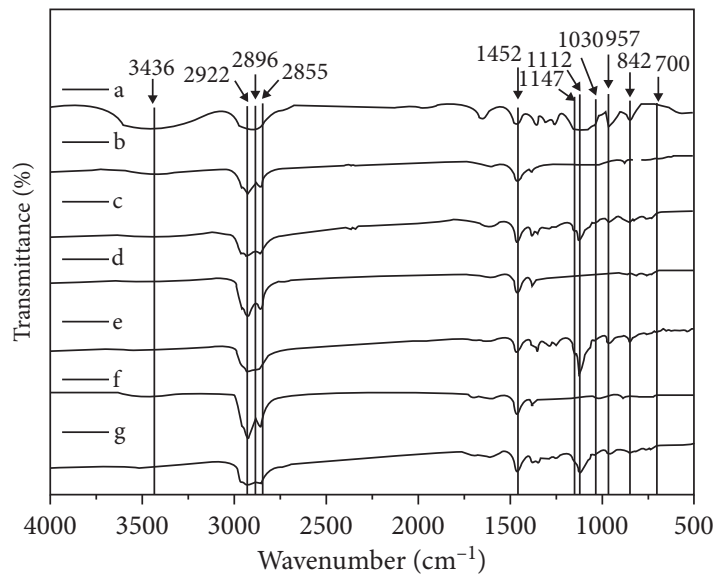

FIgURE 5: FTIR spectra obtained from PEG (a), unaged A-70 base asphalt (b), unaged 10\% PEG-modified asphalt (c), RTFOT aged A70 base asphalt (d), RTFOT aged 10\% PEG-modified asphalt (e), PAV aged A-70 base asphalt (f), and PAV aged 10\% PEG-modified asphalt $(\mathrm{g})$.

PEG appear in the spectrum of unaged 10\% PEG-modified asphalt. Therefore, PEG is physically dispersed into asphalt without undergoing chemical reactions.

Figures $5(\mathrm{~d})-5(\mathrm{~g})$ show the FTIR absorption spectrum of the base asphalt and PEG-modified asphalt after RTFOT aging and of the base asphalt and PEG-modified asphalt after PAV aging, respectively. A comparative analysis of the spectrum of the base asphalt after PAV aging (see Figure 5(f)) reveals a new absorption peak at $1030 \mathrm{~cm}^{-1}$, which is indicative of the $\mathrm{S}=\mathrm{O}$ stretching vibration of benzene and is attributed to the oxidation of asphalt $-\mathrm{SH}$ groups. The remaining absorption peaks remain relatively unchanged. Note that the $1030 \mathrm{~cm}^{-1}$ absorption peak appears in the spectrum of PEG-modified asphalt after PAV aging is due to the presence of PEG (shown in Figure 5(g)), which indicates that PEG-modified asphalt has better antiaging properties than the base asphalt. The reasons for the improvement of antiaging properties is that the capillary force and hydrogen bond are the force to stabilize the melted PEG in asphalt, so the aging degree of modified asphalt is significantly reduced during the aging process. These results indicate that the reaction between PEG and asphalt is not chemical change. In conclusion, the addition of PEG improved the antiaging property of modified asphalt.

3.5.2. AFM Analysis. Figure 6 shows two-dimensional AFM images of the A-70 base asphalt and the as-prepared PEGmodified asphalts before and after aging. The macroscopic physical properties of a material are determined by its own microstructure. The "bee structure" [32] appears in all the samples, but the number and size of the "bee structure" vary between samples. Larger bees are more likely to appear on the surface of the base asphalt bitumen (Figure 6(a)), and a large number of smaller tubers appear on the surface of the PEG-modified asphalt (Figure 6(b)). Comparing the AFM images of base asphalt before and after aging (Figures 6(a), $6(\mathrm{c})$, and 6(e)), it shows that the smaller and more tubers appear on the surface of the asphalt after aging. Nevertheless, the AFM images of PEG-modified asphalt before and after aging (Figures 6(b), 6(d), and 6(f)) show no significant change in the tubers, which indicates that the properties of the PEG-modified asphalt change little after aging.

Comparing the AFM images of base asphalt and PEGmodified asphalt before aging (Figures 6(a) and 6(b)), it shows that more and smaller bees appear on the surface of PEG-modified asphalt before aging. Because of the addition of PEG, the number of "bee structure" increases and the plane size of "bee structure" reduces, making the viscosity of 
$63.8 \mathrm{~nm}$

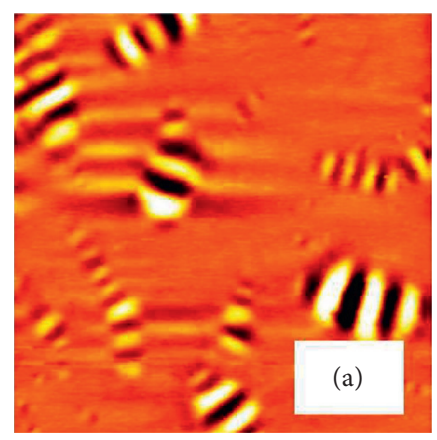

Height sensor

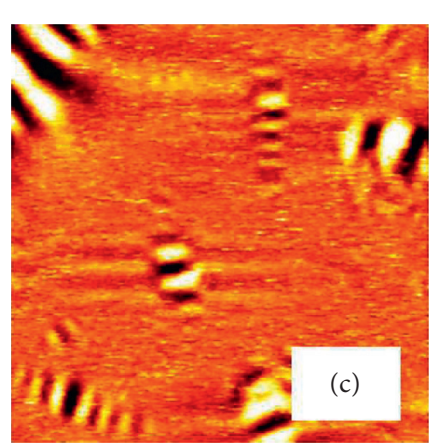

Height sensor

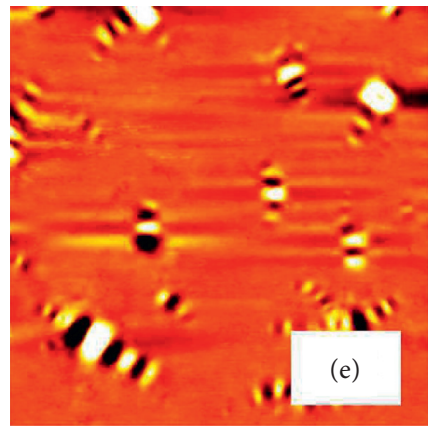

Height sensor

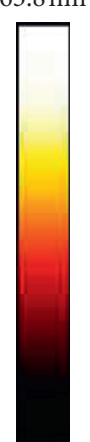

$-59.2 \mathrm{~nm}$

$56.2 \mathrm{~nm}$

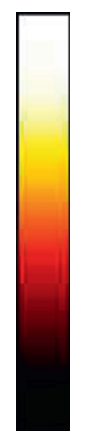

$-54.5 \mathrm{~nm}$

$30.9 \mathrm{~nm}$

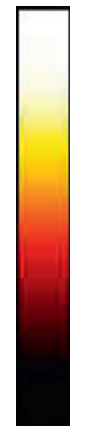

$\overline{2.0 \mu \mathrm{m}}-26.0 \mathrm{~nm}$

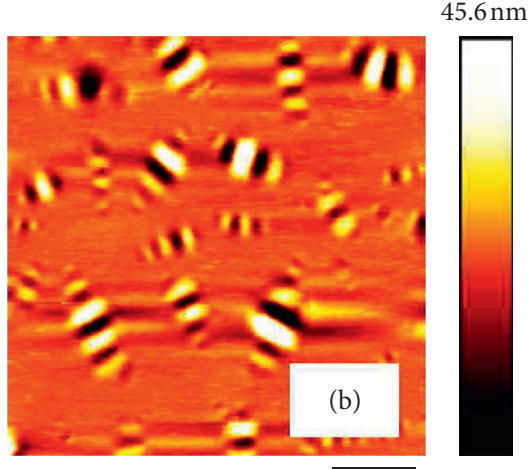

Height sensor $\quad \overline{2.0 \mu \mathrm{m}}-41.3 \mathrm{~nm}$

$42.5 \mathrm{~nm}$

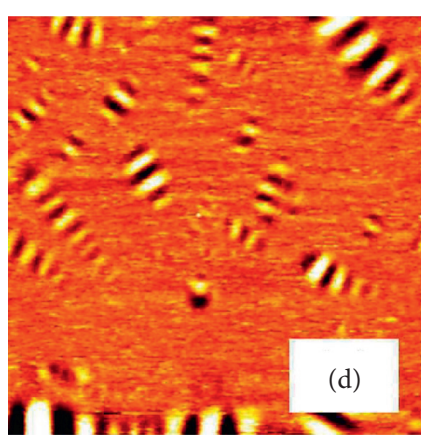

Height sensor

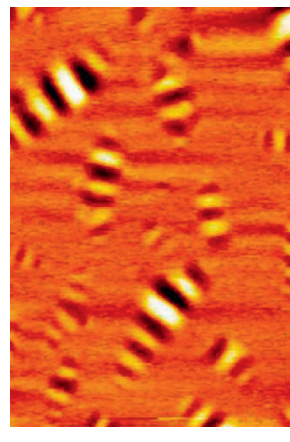

Height sensor $\overline{2.0 \mu \mathrm{m}}-40.9 \mathrm{~nm}$

$63.5 \mathrm{~nm}$
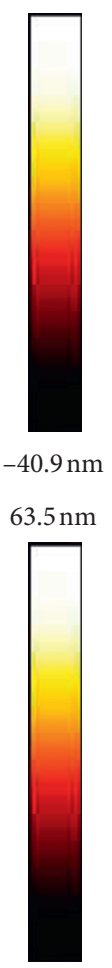

(f)

$\overline{2.0 \mu \mathrm{m}}-55.6 \mathrm{~nm}$

Figure 6: Two-dimensional (2D) AFM pictures of unaged A-70 base asphalt (a), unaged 10\% PEG-modified asphalt (b), RTFOT aged A-70 base asphalt (c), RTFOT aged 10\% PEG-modified asphalt (d), PAV aged A-70 base asphalt (e), and PAV aged 10\% PEG-modified asphalt (f).

modified asphalt greater than that of base asphalt and restricting the movement of asphaltene molecules. The formation of the asphaltic "bee structure" is a complex problem influenced by many factors (e.g., wax form, cooling rate, component content, and flow properties) [33, 34].

Comparing the AFM images of RTFOT aged and PAV aged base asphalt before and after aging (Figures 6(c) and 6(e)), it shows that larger bees appear on the surface of RTFOT aged base asphalt, which is mainly attributed to oxidation reactions and the increasing viscosity of the asphalt. Obviously, a large number of tubers with smaller size appeared on the surface of the base asphalt after aging (Figures 6(a), 6(c), and 6(e)). And the influence of PAV aging is more significant than the short-term aging on account of asphaltene. The number of wax increases as the asphaltene increases of different degree of asphalt aging, which causes that the ability of diffusivity weaken, viscosity increase, and particle migration slow down [35]. Comparing the AFM images of PEG-modified asphalt before and after aging (Figures 6(b), 6(d), and 6(f)), it shows no significant change in the tubers, which indicates that the properties of the PEG-modified asphalt remain stable after aging.

In order to quantitatively analyse the difference between the microscopic phase states of asphalt, some scholars proposed to use the roughness index to quantify the microscopic information of different asphalt. Allen used the root mean square (RMS) roughness index to study the phase difference of asphalt at the microscale [36]. Sun et al. found that the RMS roughness can take into account the area and size characteristics of bee structure [37]. The greater the 
roughness, the greater the difference in phase state of asphalt at microscopic scale, which means that the phase separation phenomenon is more significant. According to the relevant roughness standards issued by ASME, RMS roughness (nm) is adopted in this paper to characterize the difference between the microscopic phase states of asphalt. The definition is shown in the following formula:

$$
R_{q}=\sqrt{\frac{\iint\left[h(x, y)-h_{0}\right]^{2} \mathrm{~d} s}{\iint \mathrm{d} s}}
$$

where $S$ is the size of AFM image scanning area, and in this paper, the scanning range is $20 \mu \mathrm{m}^{*} ; h(x, y)$ is the height function of morphology, $\mathrm{nm} ; h_{0}$ is the reference height, $\mathrm{nm}$.

The module of "Roughness" in NanoScope Analysis software is used to measure RMS Roughness of base asphalt and PEG-modified asphalt under different aging conditions. The test results are shown in Table 4.

It can be seen from Table 4 that the addition of PEG improved the surface roughness of asphalt and increased the difference between the phase states of "bee structure" and "non-bee structure" of asphalt. The results were directly related to the increase in the number of "bee structure" of PEGmodified asphalt in the two-dimensional AFM images in Figure 6. Asphalt surface roughness decreases with the deepening of aging degree, which will lead to the migration of asphalt components and the decrease of saturation content. In the aging process, the aromatic part gradually changes to the gelatinous, the gelatinous changes to the asphaltene, and the asphaltene content increases. The multicomponent phase state of asphalt becomes "homogenized" gradually, which will lead to the decrease of the difference.

After short-term aging, the surface roughness of base asphalt decreased by $26.44 \%$, and the surface roughness of PEG-modified asphalt decreased by $6.04 \%$. After long-term aging, the surface roughness of base asphalt decreased by $41.03 \%$ and the surface roughness of PEG-modified asphalt decreased by $16.11 \%$. From the perspective of surface roughness reduction, PEG-modified asphalt was smaller than base asphalt, indicating that the addition of PEG could alleviate the change of phase state of "bee structure" under aging action. The change of phase state of "bee structure" during aging can to a certain extent represent the aging process of asphalt at the microscale. Therefore, PEG-modified asphalt has better antiaging performance than base asphalt.

\section{Conclusions}

In this study, the PEG-modified asphalt binder was prepared to evaluate the effect of PEG on asphalt performance. The results show that PEG can improve the high temperature properties of asphalt, and as manifested by the softening point and viscosity being improved. The PEG changes from solid to liquid at the high temperature during the reparation of phase change modified asphalt. With the increase of PEG
TABle 4: Roughness of modified asphalt (nm).

\begin{tabular}{lcc}
\hline Types of asphalt & Aging state & $\mathrm{Rq}(\mathrm{nm})$ \\
\hline \multirow{3}{*}{ Base asphalt } & Unaged & 32.9 \\
& RTFOT aged & 24.2 \\
& PAV aged & 19.4 \\
\hline \multirow{2}{*}{ PEG-modified asphalt } & Unaged & 14.9 \\
& RTFOT aged & 14.0 \\
& PAV aged & 12.5 \\
\hline
\end{tabular}

content, the temperature sensitivity of PEG-modified asphalt decreased gradually, which shows by the PI of PEGmodified asphalt increasing gradually. The heat absorption and temperature sensitivity of asphalt decreased effectively with the increase of PEG content.

The temperature regulation research methodology was used to evaluate the temperature adjustment and thermal performance of the PEG-modified asphalt. The results show that the temperature relief is the most pronounced and the highest temperature variation of the temperature-adjusting asphalt specimens is $\sim 13.5^{\circ} \mathrm{C}$ when the content of PEG is $10 \%$. When the heating temperature of asphalt increases and reaches the phase change temperature of PEG, PEG will absorb a lot of heat and change the phase state, which reduces the relative heat absorption of asphalt and reduces the heating rate of asphalt.

And the cracking properties of PAV aged PEG-modified asphalt with different dosages and base asphalt at low temperature were tested by BBR tests. The antiaging properties of PAV aged PEG-modified asphalt were increased compared with that of PAV aged base asphalt, and the low-temperature partition of the asphalt was not reduced. The modification and antiaging mechanism was characterized by FTIR and AFM, which indicates only physical blending between PEG and asphalt. The capillary force and hydrogen bond are the force to stabilize the melted PEG in the pores PEG-modified asphalt. Comparing the two-dimensional AFM images of the A-70 base asphalt and the as-prepared PEG-modified asphalts before and after aging indicates that smaller "bee structures" appear on the surface of PEG-modified asphalt and that these structures do not change during aging.

\section{Data Availability}

The data used to support the findings of this study are available from the corresponding author upon request.

\section{Conflicts of Interest}

The authors declare no conflicts of interest.

\section{Acknowledgments}

This work was supported by the Applied Basic Research Projects of China's Ministry of Transport (no. 2015319817150) and the Shandong Jiaotong University "Climbing" Research Innovation Team Program. 


\section{References}

[1] R. Ren, "Preparation of $\mathrm{PEG} / \mathrm{TiO}_{2} /$ graphene PCMs and its application in modified asphalt," New Chemical Materials, vol. 1, no. 2, pp. 219-222, 2019.

[2] E. Carnielo and M. Zinzi, "Optical and thermal characterisation of cool asphalts to mitigate urban temperatures and building cooling demand," Building and Environment, vol. 60, no. 5, pp. 56-65, 2013.

[3] X. Zhang, Preparation and research of the composite shapestabilized phase chang materials applied to cooling pavement, Ph.D. thesis, Zhejiang Ocean University, Zhejiang, China, 2018.

[4] Z. Liu, Y. Wang, J. Jia, H. Sun, H. Wang, and H. Qiao, "Preparation and characterization of temperature-adjusting asphalt with diatomite-supported PEG as an additive," Journal Materials in Civil Engineering, vol. 32, no. 3, 2020.

[5] C. Xavier, D. Nicaise, and S. Rachidi, "The use of phase change materials to delay pavement freezing," in Proceedings of the XIII International Winter Road Congress, Tampere, Finland, February 2010.

[6] Z. Dong, M. Chen, and S. Wu, "Preparation of expanded graphite/polyethylene glycol composite phase change material for thermoregulation of asphalt binder," Construction Building Material, vol. 169, no. 1, pp. 513-521, 2018, https://www. sciencedirect.com/science/article/abs/pii/S0950061818304161.

[7] M. Zhu, "Application of phase change temperature-regulating material in road design and construction," Research on Urban Construction Theory, vol. 33, p. 118, 2018.

[8] X. Zhou, B. Ma, Y. Ren, and X. Wang, "Study on temperature control performance of composite shaped phase chang material for asphalt pavement," Bulletin of the Chinese Ceramic Society, vol. 37, no. 11, pp. 3611-3616, 2018.

[9] S. Ye, Synthesis of microencapsulated phase change material and application in asphalt, Ph.D. thesis, Harbin Institute of Technology, Harbin ,China, 2018.

[10] Y. Zhang, H. Zhu, J. Li, and L. He, "Selection of phase chang materials used in heat storage cooling asphalt pavemengt," Journal of Zhengzhou University, vol. 33, no. 3, pp. 10-14, 2012.

[11] A. C. Andrey and B. Y. B. Chan, "Novel form-stable phase change material composite for high-efficiency room temperature control," Solar Energy Material Solar Cells, vol. 170, pp. 13-16, 2017.

[12] S. P. Wu, M. Y. Chen, and J. Z. Zhang, "Laboratory investigation into thermal response of asphalt pavements as solar collector by application of small-scale slabs," Applied Thermal Engineering, vol. 31, no. 10, pp. 1582-1587, 2011.

[13] S. Wu, J. Qiu, L. Mo, J. Yu, Y. Zhang, and B. Li, "Investigation of temperature characteristics of recycled hot mix asphalt mixtures," Resources, Conservation and Recycling, vol. 51, no. 3, pp. 610-620, 2007.

[14] L. Zhang, C. Li, and G. Que, "The adsorption behavior of petroleum asphaltene-I: adsorption mechanism and research methods," Petroleum Asphalt, vol. 5, pp. 23-28, 2007.

[15] J. Jing, L. Yang, W. Qin, and P. Luo, "Study on mechanism of waxy crude oil structure formation," Journal of Southwest Petroleum Institute, vol. 6, pp. 49-52, 2003.

[16] S. S. Shi, Y. M. Wang, and A. Q. Zhang, "Study on anti-ultraviolet radiation aging property of $\mathrm{TiO}_{2}$ modified asphalt," Advanced Materials Research, vol. 306, no. 1368, pp. 951-955, 2011.

[17] L. He, Experimental study of low-temperature rubber asphalt stiffness modulus, Ph.D. thesis, Jilin University, Jilin, China, 2015.
[18] X. Gan, N. Zhang, and Y. Liu, "Research on performance of PEG modified asphalt," Highway, vol. 59, no. 10, pp. 226-229, 2014.

[19] W. Kong, Z. Liu, Y. Yang, C. Zhou, and J. Lei, “Preparation and characterizations of asphalt/lauric acid blends phase change materials for potential building materials," Construction and Building Materials, vol. 152, pp. 568-575, 2017.

[20] X. Bian, Y. Q. Tan, J. F. Lv, and L. Y. Shan, "Preparation of latent heat materials used in asphalt pavement and theirs' controlling temperature performance," Advanced Engineering Forum, vol. 5, pp. 322-327, 2012.

[21] L. Feng, S. Zhou, S. Chen et al., "Preparation of low-temperature phase change materials microcapsules and its application to asphalt pavement," Journal Material Civil Engineering, vol. 3011 pages, 2018, https://www.researchgate. net/deref/http\%3A\%2F\%2Fdx.doi.org\%2F10.1061\% 2F(ASCE)MT.1943-5533.0002514.

[22] D. Wu and W. Ji, "The influence of different content of diatomite on the low temperature performance of silicon modified asphalt," Hei Long Jiang Jiaotong Keji, vol. 42, no. 5, pp. 55-57, 2019.

[23] F. Ma, W. Dong, Z. Fu, J. Dai, X. Chang, and B. Wang, "Low temperature performance of compound modified asphalt with SEBS and rubber powder based on rheology," Journal of Functional Materials, vol. 50, no. 6, pp. 6083-6087, 2019.

[24] L. Ji, Research on the microscopic characteristics of SBS modified asphalt before and after aging based on AFM, Ph.D. thesis, Inner Mongolia University of technology, Inner Mongolia, China, 2019.

[25] S. Hu, Q. Li, S. Huang, and Q. Ding, "Feasibility study on phase change material-polyethylene glycol used in asphalt mixture," Highway, vol. 7, pp. 291-295, 2007.

[26] J. Chen, W. Wang, Y. Sun, J. Liu, and B. Xu, "Analysis of low temperature performance and aging resistance of asphalt binder based on BBR and FT-IR," Journal of China \& Foreign Highway, vol. 39, no. 1, pp. 200-205, 2019.

[27] X. Hou, S. Lv, Z. Chen, and F. Xiao, "Applications of Fourier transform infrared spectroscopy technologies on asphalt materials," Measurement, vol. 121, pp. 304-316, 2018.

[28] H. B. Jemison, B. L. Burr, R. R. Davison, J. A. Bullin, and C. J. Glover, "Application and use of the atr, $\mathrm{ft}$-ir method to asphalt aging studies," Fuel Science and Technology International, vol. 10, no. 4-6, pp. 795-808, 1992.

[29] J. Glover, F. Lin, R. Liu et al., "Preparation and thermal properties of mineral-supported polyethylene glycol as formstable composite phase change materials (CPCMs) used in asphalt pavements," Scientific Reports, vol. 7, no. 1, 2017.

[30] L. Loeber, O. Sutton, J. Morel, J.-M. Valleton, and G. Muller, "New direct observations of asphalts and asphalt binders by scanning electron microscopy and atomic force microscopy," Journal of Microscopy, vol. 182, no. 1, pp. 32-39, 1996.

[31] Y. Ruien, X. Zhu, J. Hu, W. Zhao, and C. Fang, "Preparation of graphene oxide and its modification effect on base asphalt," Fullerenes, Nanotubes and Carbon Nanostructures, vol. 27, no. 3, pp. 256-264, 2019.

[32] A. T. Pauli, R. W. Grimes, A. G. Beemer, T. F. Turner, and J. F. Branthaver, "Morphology of asphalts, asphalt fractions and model wax-doped asphalts studied by atomic force microscopy," International Journal of Pavement Engineering, vol. 12, no. 4, pp. 291-309, 2011, https://www.researchgate. net/scientific-contributions/JF-Branthaver-2002262732.

[33] L. Branthaver, R. Grover, D. N. Little, and B. Amit, "Structural characterization of micromechanical properties in asphalt 
using atomic force microscopy," Journal of Material in Civil.Engineering, vol. 24, no. 10, pp. 1317-1327, 2012.

[34] M. Ren, "Study on modification mechanism and microproperties of poly-phosphoric acid modified asphalt considering aging performance based on AFM," Ph.D. thesis, Inner Mongolia University of Technology, Inner Mongolia, China, , 2018.

[35] P. K. Das, N. Kringos, and B. Birgisson, "Microscale investigation of thin film surface ageing of bitumen," Journal of Microscopy-Oxford, vol. 254, no. 2, 2014.

[36] Texas A\&M University, Properties in Asphalt Using Atomic Force Microscopy, Texas A\&M University, College Station, TX, USA, 2010.

[37] G. Sun, P. Qi, and D. Sun, "The progress of asphalt microcosmic structure research based on AFM," Petroleum Asphalt, vol. 30 , no. $4,2016$. 